\title{
TRUE EXTRAMURAL DIVERTICULUM ON THE LATERAL WALL OF THE SECOND PART OF DUODENUM
}

\section{Saleena N Ali ${ }^{1}$, Suma H Y ${ }^{* 2}$, Yogesh Sontakke ${ }^{3}$, Aravindhan $\mathrm{K}^{4}$.}

${ }^{1}$ Junior resident, Department of Anatomy, Jawaharlal Institute of Postgraduate Medical Education \& Research (JIPMER), Pondicherry, India.

*2 Additional Professor, Department of Anatomy, Jawaharlal Institute of Postgraduate Medical Education \& Research (JIPMER), Pondicherry, India.

${ }^{3}$ Assistant Professor, Department of Anatomy, Jawaharlal Institute of Postgraduate Medical Education \& Research (JIPMER), Pondicherry, India.

${ }^{4}$ Additional Professor and HOD, Department of Anatomy, Jawaharlal Institute of Postgraduate Medical Education \& Research (JIPMER), Pondicherry, India.

\section{ABSTRACT}

The duodenum is the second most common site for diverticulum in the gastrointestinal tract after the colon. The extramural duodenal diverticula are common on the medial wall of second part of duodenum due to the opening of the hepatopancreatic duct. The incidence of duodenal diverticula on the lateral wall of the duodenum is only three percent. The present article reports an extramural diverticulum opening in the anterolateral wall of second part of duodenum proximal to the major duodenal papilla in an adult female cadaver. The diverticulum showed all the four layers of the duodenal wall on histological examination. The duodenal diverticula are usually asymptomatic, but if complications develop, the patient may present with non- specific abdominal symptoms, making the clinical diagnosis difficult. Because of this clinical significance, knowledge of such variations may be helpful for surgeons and gastroenterologists who deal with such cases.

KEY WORDS: Diverticulum, major duodenal papilla, Brunner's glands.

Address for Correspondence: Dr. Suma H Y, Additional Professor, Department of Anatomy, Academic center, JIPMER, Pondicherry 605006, India. Phone No- 9442550603

E-Mail:suma_1478@gmail.com

\section{Access this Article online}

\section{Quick Response code}

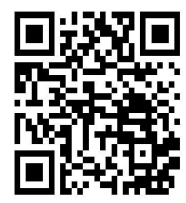

DOI: $10.16965 /$ ijar.2017.147

Web site: International Journal of Anatomy and Research

ISSN 2321-4287

www.ijmhr.org/ijar.htm

Received: 12 Feb 2017

Peer Review: 13 Feb 2017

Revised: None
Accepted: 03 Apr 2017

Published (O): 30 Apr 2017

Published (P): 30 Apr 2017

\section{INTRODUCTION}

A diverticulum is an outpouching of a hollow organ of the body like gastrointestinal tract. The duodenum is the second most common site for diverticulum in the gastrointestinal tract after the colon. Duodenal diverticula can be classified as true or false, intramural or extramural, congenital or acquired [1]. The intramural intestinal diverticulum is always congenital and rare.
Extramural diverticula, the more common variety, are usually acquired [2].

The extramural diverticula can be periampullary diverticula (adjacent to or contain the major duodenal papilla) or juxta-papillary diverticula (lie within the radius of two centimeters of major duodenal papilla but do not include the major duodenal papilla) [3]. The juxta-papillary diverticula on the medial wall of the duodenum 
are the most common type of duodenal diverticula, the incidence being $53 \%$, followed by periampullary $(18 \%)$. The incidence of duodenal diverticula on the lateral wall of the duodenum and the fourth part is three percent, whereas it is only one percent on the third part of duodenum [2]. The present article reports a case of duodenal diverticulum, as it is rare and can add to the frequency of its variation.

\section{CASE REPORT}

During routine anatomical dissection of the abdomen as per the Cunningham's manual, a duodenal diverticulum was observed related to the second part of duodenum in a female cadaver of approximately 65 years age. It was sessile, spherical in shape and $2 \times 2 \mathrm{~cm}$ in size. It was located seven $\mathrm{cm}$ distal to the pyloric sphincter and three $\mathrm{cm}$ distal to the superior duodenal flexure on the right lateral border of the duodenum (Figure 1). It was anteriorly related to the transverse mesocolon and right lobe of the liver and posteriorly to the anterior surface of the right kidney and superiorly to the right lobe of the liver. As the second part of the duodenum, diverticulum was also covered by a layer of the peritoneum anteriorly. The wall of the diverticulum was thin compared to that of the duodenum.

A vertical incision was given along the anterior surface of the second part of the duodenum to look for the diverticular opening. Interior of the duodenum showed numerous folds (valves of Kerkrings). On internal examination, the oval opening of the diverticulum, measuring four $\mathrm{mm}$ in diameter, was seen on the anterolateral wall of the duodenum (Figure 2A). The opening was located two $\mathrm{cm}$ proximal to the major duodenal papilla (Figure 2A). A horizontal incision on the wall of the second part of duodenum and diverticulum was given to examine the interior of the diverticulum. The lumen of the diverticulum was smooth and did not show any circular folds or plica circularis as in the duodenum (Figure 2B). For histological examination, tissue sections were taken from the diverticulum and the duodenal wall. Tissues were processed through ascending series of alcohol followed by three changes of xylene and paraffin. Sections of seven $\mu \mathrm{m}$ thickness were prepared from each paraffin embedded block. The sections were further stained with routine hematoxylin and eosin.

On examination of the stained slides, the wall of the duodenum, as well as the diverticulum, showed the four layers, namely, mucosa, submucosa, muscularis externa and serosa (Figure $3 \mathrm{~A}$ and $\mathrm{BB}$ ). But, the microstructure of the layers was different. The mucosal villi were poorly developed in the diverticulum, the Brunner's glands (mucous secreting glands) in the submucosa were absent, and the muscularis externa was thin compared to the duodenal wall.

Fig. 1: Extramural diverticulum from the lateral wall of the second part of duodenum.

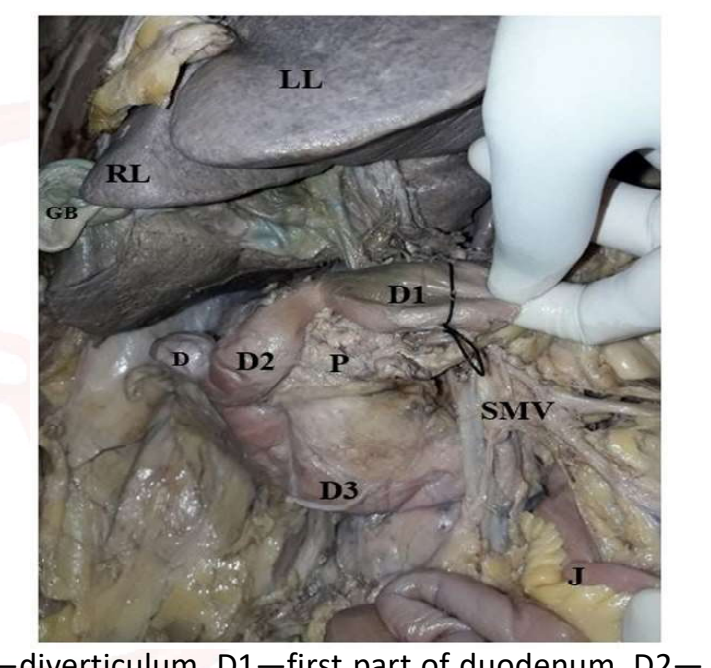

D-diverticulum, D1-first part of duodenum, D2second part of duodenum, D3 - third part of duodenum, GB-gall bladder, J-jejunum, LL-left lobe of liver, $\mathrm{P}$-pancreas, RL-right lobe of liver, SMVsuperior mesenteric vessels.

Fig. 2: Luminal details of the duodenum and the diverticulum. A. Interior of the duodenum showing the opening of the diverticulum (white arrow) on the anterolateral wall of the duodenum. The opening was located proximal to the major duodenal papilla (black arrow) B. Interior of the diverticulum. Plica circularis (PC) were absent in the diverticulum. The duodenodiverticular junction is indicated by dotted line.

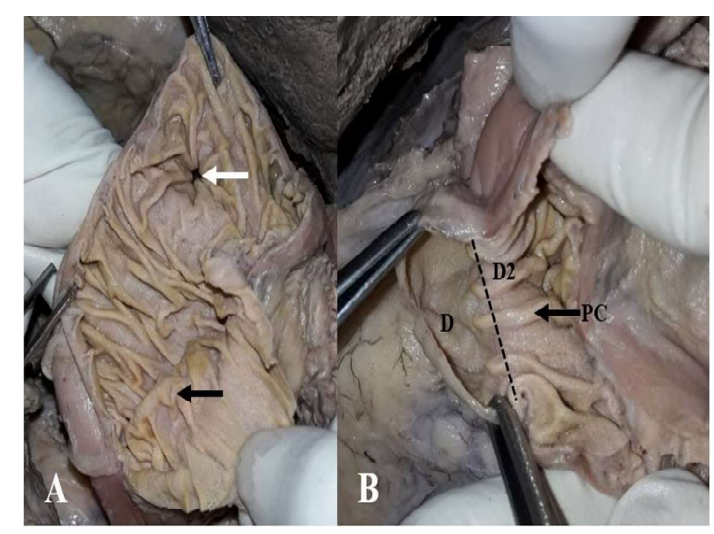

D-diverticulum, D2-second part of duodenum. 
Fig. 3: Microanatomic structure of the wall of the duodenum (A) and diverticulum (B). The duodenum showed the presence of four layers as mucosa (M), submucosa (SM), muscularis externa (ME) and serosa (S). Submucosal mucous glands - Brunner's glands (BG) were present. The diverticulum also showed all four layers. In the diverticulum, the villi (V) were not well developed, Brunner's glands were absent, and musclularis externa was thin as compared to the duodenal wall.

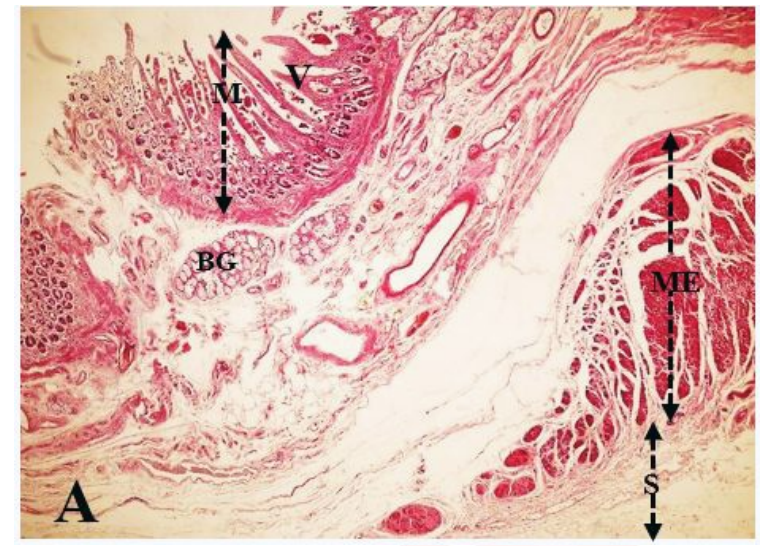

\section{DISCUSSION}

The duodenal diverticulum was first reported in the eighteenth century by Chomall. The small intestinal diverticula are most common in the duodenum, followed by jejunum and ileum. The extramural diverticula protrude outside the wall of the duodenum whereas the intramural are present within its lumen. A duodenal diverticulum can be true if the wall consists of all the four layers (mucosa, submucosa, muscularis externa and serosa) as that of the duodenum. A false diverticulum contains either mucosa alone or mucosa and submucosa [3]. The extramural diverticula, usually being false, sometimes may consist of scattered muscle cells representing the musclaris externa [4]. The diverticulum present in this cadaver, even though being extramural, showed the four layers on histological examination, and hence it can be classified as a true diverticulum. But the absence of Brunner's glands, the poorly developed villi and the thin muscular layer in the diverticulum were not possible to explain from the literature.

An intramural diverticulum develops as solitary sac attached to the entire circumference or only a part of the duodenal wall. The abnormal recanalizing of the lumen of the duodenum in early fetal life can lead to the formation of duodenal diaphragm or web. After birth, over a period, these can be transformed to intraluminal diverticula due to peristaltic stretching. The occurrence of such diverticula is very rare and has been reported only in less than 100 patients [2]. The extramural duodenal diverticula usually

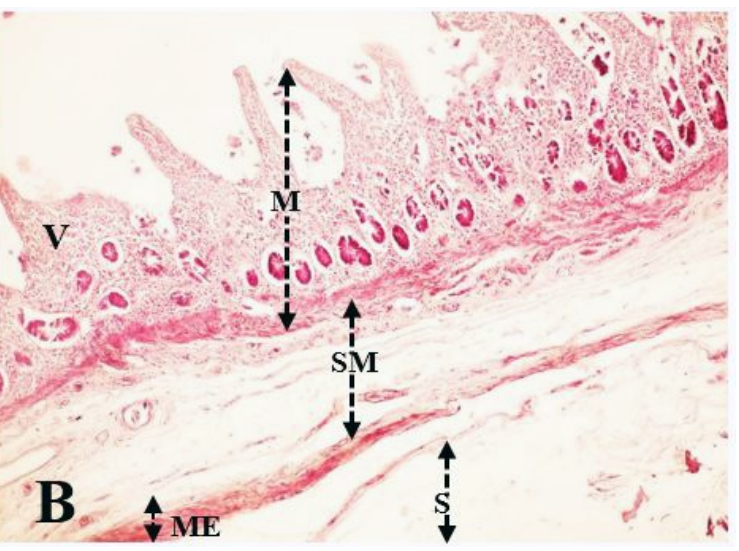

occur in the areas of small defects in the muscular wall due to the entry point of the blood vessel and the ducts [5]. The posteromedial wall is more prone to the formation of diverticula due to the opening of the common bile duct and pancreatic duct [6]. The high intraluminal duodenal pressure can also lead to the herniation of the mucosa and submucosa through the weak areas of the muscular wall [7].

The duodenal diverticula are more commonly seen in females after the fifth decade. The incidence is more as age increases [8]. Usually, these diverticula are asymptomatic. When complications develop, due to inflammation or accumulation of food particles, they produce non-specific symptoms like abdominal pain, nausea, vomiting. The periampullary diverticula can produce symptoms simulating choledocholithiasis, gallstones due to the blockage of the common bile duct. The pouch of the diverticulum, if filled with food particles, can lead to bacterial overgrowth and thus, diverticulitis and formation of an abscess. The enlarged pouch can compress the pancreas resulting in pancreatitis [8]. Diverticulitis is the most common cause for perforation of duodenal diverticulum even though it is a very rare complication [9].

However, the most commonly encountered complication is bleeding [8] A duodenal diverticulum situated on the lateral wall was reported by surgeons in Turkey in 2015 [10]. The endoscopic examination showed a diverticulum of five $\mathrm{cm}$ contained with food residues. In 2005, a similar case was reported in Romania with the 
size of the diverticulum being only two $\mathrm{cm}[11]$. Both patients presented with symptoms like pain over right hypochondriac and epigastric region, nausea and emesis due to diverticulitis. Laparoscopic resection of the diverticulum was performed by the surgeons, and the patients were asymptomatic postoperatively.

The diagnosis can be established by an upper gastrointestinal endoscopic examination, computed tomography, magnetic resonance imaging or using contrast studies. However, if the diverticular pouch is small, it may not get filled with the contrast material like barium, leading to false-negative results [12].

Depending on the mode of diagnosis, the prevalence of the duodenal diverticula varies. These are present in $5 \%$ to $10 \%$ in barium radiographic series, $22 \%$ of autopsy findings [9] and $9 \%$ to $23 \%$ at endoscopic retrograde cholangio pancre atography [11]. Asymptomatic diverticula can be left alone. Surgical resection through laparotomy is the preferred for patients developing complications. Laparoscopic resection is the treatment of choice for symptomatic diverticula on the lateral wall of the duodenum $[10,11]$.

Periampullary and juxta-papillary outgrowths are harder to treat compared to the lateral diverticula due to associated biliary and pancreatic pathologies.

\section{CONCLUSION}

The present case is a rare entity since it shows a true extramural diverticulum on the convex border of the duodenum. The presence of these diverticula should be kept in mind while performing diagnostic procedures for gastrointestinal diseases as the early diagnosis may help the patients.

\section{Conflicts of Interests: None}

\section{REFERENCES}

[1]. McKenzie S, Evers BM. Small intestine. In: Townsend MC, Beauchamp RD, Evers BM, Mattox KL editors. Sabiston Textbook of Surgery $19^{\text {th }}$ edition. Philadelphia: Elsevier Saunders Co;2012.pp.1227-93.

[2]. Vagholkar K, Tople S. Duodenal diverticulum. The Internet Journal of Surgery. 2012;28(4):1-4.

[3]. Mahajan SK, Kashyap R, Chandel UK, Mokta J, Minhas SM. Duodenal diverticulum: Review of literature. Indian Journal of Surgery. 2004;66(3):140-5.

[4]. Kua J, Seah A, So J. Periampullary diverticulum: A case of bleeding from periampullary diverticula. Ann Acad Med Singapore. 2005;34:636-8.

[5]. Rizwan MM, Chandar VP,Zulfiqar M, Singh V. Duodenal diverticulum and associated pancreatitis: Case report with brief review of literature. World J Gastrointest Endosc. 2011;3(3):62-3.

[6]. Edwards H. Diverticulum of second part of duodenum. Proc R Soc Med. 1933;26(7):827

[7]. Standring S, ed. Gray's Anatomy. The Anatomical Basis of Clinical Practice. $41^{\text {st }}$ Ed. Elsevier. 2016.pp.1126.

[8]. Fotiades $\mathrm{Cl}$, Kouerinis IA, Papandreou I, Pilichos C, Zografos G, Mahairasi A. Current diagnostic and treatment aspects of duodenal diverticula: report of two polar case and review of literature. Annals of Gastroenterology. 2005;18(4):441-4.

[9]. Thorson CM, Ruiz PSP, Roeder RA, Sleeman D, Casillas VJ. The perforated duodenal diverticulum. Arch Surg. 2012;147(1):81-8.

[10]. Ekici Y, Moray G. Large duodenal diverticula treated by laparoscopic surgical excision: a case report. J Minim Invasive Surg Sci. 2015;4(2):e30196.

[11]. Graur F, Bala O, Bodea R, Greczi-Toth I, Vlad L, lancu C. Laparoscopic resection of duodenal diverticulum. A case report. Romanian Journal of Gastroenterology. 2005;14(4):405-8.

[12]. Akhrass R, Yaffe MB, Fischer C, Ponsky J, Shuck JM. Small-bowel diverticulosis: perceptions and reality. J Amer Coll Surg. 1997;184:383-8.

How to cite this article:

Saleena N Ali, Suma H Y, Yogesh Sontakke, Aravindhan K. TRUE EXTRAMURAL DIVERTICULUM ON THE LATERAL WALL OF THE SECOND PART OF DUODENUM. Int J Anat Res 2017;5(2.1):37043707. DOI: $10.16965 /$ ijar.2017.147 